\title{
A prospective study to compare the efficacy and safety of tioconazole and clotrimazole vaginal gel in patients suffering from vulvovaginal candidiasis
}

\author{
Rahul V. Mayekar ${ }^{1 *}$, Khushboo V. Kandhari ${ }^{1}$, Archana A. Bhosale ${ }^{1}$, Yogeshwar S. \\ Nandanwar ${ }^{1}$, Sumedh M. Gaikwad ${ }^{2}$
}

\begin{abstract}
${ }^{1}$ Department of Obstetrics and Gynaecology, Lokmanya Tilak Municipal Medical College and General Hospital, Mumbai, Maharashtra, India

${ }^{2}$ Department of Medical Services, Themis Medicare Limited, Mumbai, Maharashtra, India
\end{abstract}

Received: 25 October 2016

Accepted: 28 October 2016

\section{*Correspondence:}

Dr. Rahul V. Mayekar,

E-mail: rvmayekar@gmail.com

Copyright: () the author(s), publisher and licensee Medip Academy. This is an open-access article distributed under the terms of the Creative Commons Attribution Non-Commercial License, which permits unrestricted non-commercial use, distribution, and reproduction in any medium, provided the original work is properly cited.

\section{ABSTRACT}

Background: Vulvo vaginal candidiasis is an extremely common gynaecological condition. While clotrimazole has been the mainstay of treatment of this pathology, newer medications are now available. The study aims to compare the efficacy, compliance and safety of tioconazole single dose intravaginal gel application and clotrimazole vaginal gel for 3 days in patients suffering from vulvovaginal candidiasis.

Methods: A prospective, multicentric, open label, randomized, controlled, parallel group clinical trial of 220 women with 110 in each group for the evaluation of the effects of tioconazole vaginal gel in patients suffering from candidial vaginitis. Patients were divided into two groups; Group I received tioconazole vaginal gel as topical single dose therapy administered by the treating doctor and Group II received clotrimazole vaginal gel self-administered by the patient for three days. Response to therapy in both groups was studied and compared.

Results: At the end of day 7, mean score of vaginal discharge quantity had a fall of $93.3 \%$ and $92.3 \%$ in tioconazole and clotrimazole group respectively but difference was statistically insignificant. Microbiological cure rate in both the groups was similar. Reduction of vaginal irritation, vaginal itching, vaginal burning, pain in the vulval area, pain during urination or during sexual intercourse, vaginal erythema, tenderness and swelling were also comparable in both the groups.

Conclusions: Tioconazole gel single dose intravaginal application is as effective as clotrimazole gel three day intravaginal application. tioconazole is safe, well accepted and tolerated by the patients and will be useful in the treatment of vulvovaginal candidiasis.

Keywords: Clotrimazole, Tioconazole, Vaginal gel, Vulvovaginal Candidiasis

\section{INTRODUCTION}

Vaginal infections are one of the most common problems seen in gynaecological practice and sometimes pose a challenge to the treating doctor. The vagina being an ideal reservoir for infected body fluids is also likely to experience minute tears and abrasions due to intercourse, allowing entry for pathogenic organisms. Three major types of vaginal infections recognized are trichomonal vaginitis, vulvo-vaginal candidiasis (VVC) and bacterial vaginosis, formerly called Non Specific Vaginitis (NSV) or Gardnerella vaginalis-associated vaginitis. Approximately three fourths of women experience at least one episode of vaginitis during their lifetime. ${ }^{1,2}$ 
Nearly 150 different strains of vulvovaginal candidiasis have been identified and in $80-90 \%$ of presenting cases vulvovaginal candidiasis are caused by Candida albicans which has been showing decrease susceptibility to the various topical as well as systemic antifungals. ${ }^{3}$ Further super added bacterial infections also cause an increase in the resistance to drugs used in the treatment of candidiasis. ${ }^{4}$ Existing modes of treatment for C. albicans include multiple topical imidazole or triazole antifungal compounds including clotrimazole, miconazole which are $80-90 \%$ effective, when given in a course ranging from single dose to up to 14 days. One such newer topical azole antifungal agent called tioconazole has emerged with broad spectrum activity in vitro against dermatophytes and yeasts, as well as against some chlamydia, trichomonads and Gram-positive bacteria. tioconazole has a dual mechanism of antifungal action that is inhibition of sterol biosynthesis and also direct cell membrane damage leading to leakage of cell contents. In growing cultures, it exerts a potent fungicidal action. The extent and rapidity of fungicidal effect of tioconazole was found to be more than that of miconazole and clotrimazole in animal studies. 5

Further as tioconazole has been recommended as a single dose application in vulvovaginal candidiasis it would be worth examining its efficacy in the treatment of vulvovaginal candidiasis as there is no recent study on this molecule. The study aims to compare the efficacy, compliance and safety of tioconazole vaginal gel as single dose application and clotrimazole vaginal gel for 3 days in patients suffering from candidial vaginitis

\section{METHODS}

\section{Study design}

The present study was a prospective, multicentric, open, randomized, controlled, parallel, 2-arm study to evaluate the effects of tioconazole vaginal gel in patients suffering from candidial vaginitis. After Institutional Ethics Committee approval patients were diagnosed as vulvovaginal candidiasis on the basis of history and symptoms of vaginitis, including presence of curdy white precipitate or discharge, vaginal irritation, itching and burning, painful urination with a positive Potassium hydroxide $(\mathrm{KOH})$ wet mount preparation. The baseline clinical evaluation included per speculum and per vaginal examination (PV) to look for presence of curdy white precipitate, vaginal discharge, vaginal erythema and vaginal tenderness.

The clinical and symptomatic responses to treatment were noted by Visual Analogue Score changes for both symptomatic and clinical parameters. Patients with complaints of presence of curdy white precipitate or discharge with associated symptoms, vaginal irritation, itching and burning (recorded on VAS as severe irritation/ itching / burning= 10 and no irritation/ itching/ burning as $=0$ ), painful urination (recorded on VAS as severe pain during urination $=10$ and no pain as $=0$ ) were noted on day 0 (baseline), and after completion of treatment on day 7. The amount of vaginal discharge quantity (recorded on Visual Analogue Scale (VAS) as profuse discharge $=10$ and no discharge as $=0$ ) by both the patient and the treating doctor.

Microbiological testing i.e. vaginal swab/ wet $\mathrm{KOH}$ mount was performed on prior to enrolment for confirmation of diagnosis and on day 7 for test of cure

The patients were divided into two groups of 110 each; group I received the investigational product tioconazole vaginal gel as topical therapy single dose administered by the treating doctor and group II received standard comparator clotrimazole vaginal gel as 3 day selfadministered course.

All observed or volunteered adverse events regardless of treatment group or suspected causal relationship to the study drug were recorded

\section{Statistical analysis}

Descriptive statistics was used to present the data. Chi square $\left(\chi^{2}\right)$ for trend was used for analysis of categorical data where one of the variables was ordinal. All analyses were carried out using EpiInfo version 7 and a $P$ value $<0.05$ was considered significant.

\section{RESULTS}

Table 1: Profile of patients in two treatment groups.

\begin{tabular}{|lll|}
\hline Characteristic & $\begin{array}{l}\text { Tioconazole } \\
\text { Gel }(\mathrm{N}=107)\end{array}$ & $\begin{array}{l}\text { Clotrimazole } \\
\text { Gel }(\mathrm{N}=105)\end{array}$ \\
\hline $\begin{array}{l}\text { No of patients } \\
\text { enrolled }\end{array}$ & 110 & 110 \\
\hline $\begin{array}{l}\text { No of patients lost to } \\
\text { follow up }\end{array}$ & 03 & 05 \\
\hline $\begin{array}{l}\text { No of cases analyzed } \\
\text { for efficacy }\end{array}$ & 107 & 105 \\
\hline $\begin{array}{l}\text { Mean age in years } \\
\text { (range) }\end{array}$ & $38.3(23-59)$ & $40.4(26-58)$ \\
\hline $\begin{array}{l}\text { Trial medication } \\
\text { compliance }(\%)\end{array}$ & 100 & 86.7 \\
\hline
\end{tabular}

The 220 patients were randomly divided into the two treatment groups. Three patients treated with tioconazole and five patients treated with clotrimazole did not follow up and were considered lost to follow up. All 212 patients completed the follow up and were included in the evaluation. Demographic and epidemiologic parameters were comparable for the two treatment groups (Table 1). Table 1 shows that age of the patients were ranging from 23-59 years with average age of 38.30 years in Tioconazole Gel group and 40.35 years among Clotrimazole Gel group which was same and difference was not significant. As Tioconazole was administered by 
the treating doctor itself and was given as a single dose application, compliance for treatment medication was $100 \%$ while in the clotrimazole group which was selfadministered $13.3 \%$ patients forgot to use the application at least once in the treatment course.

The overall clinical success rate was similar for the two treatment groups (Table 2). At the end of day 7, in $93.3 \%$ of 107 patients who received tioconazole, and $92.3 \%$ of 105 patients who received clotrimazole responded to treatment and vaginal discharge quantity was reduced. The patients had reduced vaginal irritation by $82.6 \%$ in both tioconazole gel and clotrimazole gel group which was same. The sensation of vaginal burning had a fallen by $89.7 \%$ among tioconazole gel group and $90.1 \%$ in clotrimazole gel group. The vaginal itching also had reduced by $85.1 \%$ and $86.8 \%$ among tioconazole gel group and clotrimazole gel group respectively at the end of 7 days. Dysuria was relieved in $88.6 \%$ and $90.7 \%$ of patients who had painful micturition in the tioconazole gel group and clotrimazole gel group respectively.

Table 2: Subjective evaluation of two treatment groups on day 7 .

\begin{tabular}{|c|c|c|}
\hline Symptomatic relief & $\begin{array}{l}\text { Tioconazole } \\
\text { Gel }(\mathbf{N}=107)\end{array}$ & $\begin{array}{l}\text { Clotrimazole } \\
\text { Gel }(\mathrm{N}=105)\end{array}$ \\
\hline $\begin{array}{l}\text { Reduction in vaginal } \\
\text { discharge quantity }\end{array}$ & $93.3 \%$ & $92.3 \%$ \\
\hline $\begin{array}{l}\text { Reduction in vaginal } \\
\text { irritation and vaginal } \\
\text { burning }\end{array}$ & $82.6 \%$ & $82.6 \%$ \\
\hline $\begin{array}{l}\text { Reduction in vaginal } \\
\text { itching }\end{array}$ & $85.1 \%$ & $86.8 \%$ \\
\hline $\begin{array}{l}\text { Reduction in pain } \\
\text { during urination } *\end{array}$ & $88.6 \%$ & $90.7 \%$ \\
\hline
\end{tabular}

(By Chi - Square Test, $\mathrm{P}>0.05$ Not Significant)

* Not all patients of vulvovaginal candidiasis reported with burning micturition. 43 patients in Tioconazole group and 47 patients in the Clotrimazole group had symptoms of dysuria which was as a result of severe irritation of the vulva and the vagina.

At Gynaecological examination at the end of the treatment $91.7 \%$ of cases among tioconazole gel group and $92.6 \%$ among clotrimazole gel group had reduction of the vaginal discharge to a thin vaginal discharge which was a significant change from pre-treatment evaluation (Table 3). Vaginal erythema was absent in $86.9 \%$ and $88.6 \%$ patients who received tioconazole gel group and clotrimazole gel group respectively. By the end of treatment, $88.8 \%$ and $84.8 \%$ of the total cases in tioconazole gel group and clotrimazole gel group respectively did not exhibit vaginal tenderness which was significant change from baseline. The change was similar among both the groups and hence difference was insignificant.
Table 3: Clinical and laboratory evaluation in the two treatment groups.

\begin{tabular}{|lll|}
\hline $\begin{array}{l}\text { Improvement of } \\
\text { clinical and laboratory } \\
\text { parameters }\end{array}$ & $\begin{array}{l}\text { Tioconazole } \\
\text { Gel (N=107) }\end{array}$ & $\begin{array}{l}\text { Clotrimazole } \\
\text { Gel (N=105) }\end{array}$ \\
\hline $\begin{array}{l}\text { Reduction in vaginal } \\
\text { discharge }\end{array}$ & $91.7 \%$ & $92.6 \%$ \\
\hline $\begin{array}{l}\text { Reduction in vaginal } \\
\text { erythema }\end{array}$ & $86.9 \%$ & $88.6 \%$ \\
\hline $\begin{array}{l}\text { Reduction in vaginal } \\
\text { tenderness }\end{array}$ & $88.8 \%$ & $84.8 \%$ \\
\hline $\begin{array}{l}\text { Negative 10\% KOH wet } \\
\text { mount }\end{array}$ & $94.4 \%$ & $93.3 \%$ \\
\hline
\end{tabular}

(By Chi - Square Test, P > 0.05 Not Significant)

The microbiological cure rate was 94.45 and $93.3 \%$ in the two groups respectively and the difference between the two groups was not statistically significant.

Table 4 shows tioconazole gel group experience a slight higher incidence of minor side effects in comparison with clotrimazole group. $9(8.2 \%)$ of the patients in the tioconazole group had symptoms slightly aggravated on administering the trial medication in comparison with 5 $(4.5 \%)$ patients in the clotrimazole group. Out of this most common was pruritis followed by burning and irritation among both the groups. The intensity of events was mild to moderate in all the cases which resolved spontaneously and did not require any treatment.

Table 4: Side effects.

\begin{tabular}{|lllll|}
\hline Side effects & \multicolumn{2}{l|}{ Tioconazole } & \multicolumn{2}{c|}{ Clotrimazole } \\
& Gel $(\mathbf{N}=\mathbf{1 1 0})$ & \multicolumn{2}{c|}{ Gel $(\mathbf{N}=110)$} \\
\hline No & $\mathbf{\%}$ & No & $\%$ \\
\hline Burning & 02 & 01.8 & 01 & 0.9 \\
\hline Irritation & 03 & 02.7 & 02 & 01.8 \\
\hline Pruritis & 04 & 03.6 & 02 & 01.8 \\
\hline Total no of patients & 09 & 08.2 & 05 & 4.5 \\
\hline
\end{tabular}

(By Chi - Square Test, P > 0.05 Not Significant)

Table 5: Overall global assessment of efficacy of formulation by the physicians.

\begin{tabular}{|lllll|}
\hline Assessment & \multicolumn{2}{l}{ Tioconazole Gel } \\
& No107) & \multicolumn{2}{l|}{$\begin{array}{l}\text { Clotrimazole Gel } \\
(\mathbf{N}=105)\end{array}$} \\
\hline No response & - & $\%$ & No & $\%$ \\
\hline Fair & 06 & 05.6 & 07 & 06.7 \\
\hline Good & 61 & 57.0 & 59 & 56.2 \\
\hline Excellent & 40 & 37.4 & 39 & 37.1 \\
\hline
\end{tabular}

(By Chi - Square Test, P > 0.05 Not Significant)

According to the Physician, 94.4\% of total cases among tioconazole gel group had well to excellent efficacy of formulation which was comparable to $93.3 \%$ among clotrimazole gel group wherein difference was insignificant (Table 5). In addition, as tioconazole was 
administered by the treating doctor it ensured $100 \%$ compliance.

\section{DISCUSSION}

Vaginitis caused by Candida species has become one of the most troublesome forms of vaginitis because it is so frequently a recurrent problem. Short-term therapy is particularly effective for the treatment of isolated episodes of VVC, but recurrence rates can range from 10 to $40 \%$. tioconazole as a single gel formulation applicaton has proved to be well efficacious and safe for the treatment of vaginal candidiasis. ${ }^{6}$ Candida albicans though quite often is the main pathogen seen in vulvovaginal candidiasis, various other candida species have also been isolated such as Candida glabrata, candida tropicalis, Candida krusei etc. ${ }^{7,8}$

The reported drug resistance to use of clotrimazole is low and while clotrimazole has been the standard treatment offered, newer medication may also be also as effective. ${ }^{9}$ Tioconazole being a single dose application administered by the treating doctor not only ensures complete compliance but also is reassuring to the patient and this probably enhances patient acceptability greatly. In addition it has also been reported that gel form provides for a longer contact time of the active component at the desired location, and results in a more efficient use of the active component and improved effectiveness Gel formulations generally provide faster drug release as compared to ointments and creams and may be useful when available. Newer and novel drug delivery systems are known to greatly enhance drug bioavailability. ${ }^{10}$

Two hundred and twenty patients suffering from vaginal candidiasis were enrolled (110 in each group) to receive either tioconazole vaginal gel or clotrimazole ointment. The compliance was $100 \%$ in the tioconazole group (being a single application administered by the treating doctor).

There was a significant reduction in the mean score of vaginal discharge seen in both the groups on day 3 (47.9\% among tioconazole gel group and $48.5 \%$ in clotrimazole gel group). At the end of day 7, mean score of vaginal discharge quantity had a fall of $93.3 \%$ and $92.3 \%$ in tioconazole gel and clotrimazole gel group respectively. Similarly there was a reduction in the thickness in the vaginal discharge in both the groups after treatment. The discharge which was thick at the start of treatment became thin after treatment. (91.6\% of cases among tioconazole gel group and $93.3 \%$ among clotrimazole gel group had thin vaginal discharge on day 7 ). The satisfactory cure rates seen with azole derivatives has also been reported in literature. ${ }^{11}$

The other parameters such as vaginal irritation, vaginal itching vaginal burning showed significant improvement in both the groups at the end of the treatment. There was a significant reduction of mean vaginal irritation $82.6 \%$ in both tioconazole gel and clotrimazole gel group.

Mean score of vaginal itching had a fall of $85.1 \%$ and $86.8 \%$ among tioconazole gel group and clotrimazole gel group respectively. At the end of 7 days, mean score of vaginal burning had a fall of $89.7 \%$ among tioconazole gel group and $90.1 \%$ in clotrimazole gel group.

There was a significant reduction observed in the mean pain scores at the end of treatment in both the groups. The pain scores compared in the study were mean pain score in the vulval region, mean pain score during urination, mean pain score during sexual intercourse, mean pain score of vaginal erythema, mean pain score of vaginal tenderness, and mean pain score of vaginal swelling. Provoked vestibulodynia is 4-7 times more common with vulvovaginal candidiasis and treatment of the cause would result in relief of the symptoms. ${ }^{12}$

About $8.2 \%$ of the total cases among tioconazole gel group experience an adverse event which was slightly more as compared to $4.5 \%$ in clotrimazole gel group wherein the difference was insignificant. Out of this most common was pruritis followed by burning and irritation among both the groups. The intensity of events was mild to moderate in all the cases which resolved spontaneously during the treatment period and these symptoms may be directly proportionate with the severity of the disease.

\section{CONCLUSION}

Tioconazole gel single dose intravaginal application is as effective as Clotrimazole gel three day intravaginal application. Tioconazole is safe, well accepted and tolerated by the patients and will be useful in the treatment of vulvovaginal candidiasis.

\section{ACKNOWLEDGEMENTS}

We are greatly thankful to Themis Medicare Ltd.

Funding: Themis Medicare Ltd.

Conflict of interest: None declared

Ethical approval: The study was approved by the Institutional Ethics Committee

\section{REFERENCES}

1. Berg AO, Heidrich FE, Fihn SD, Bergman JJ, Wood RW, Stamm WE, et al. Establishing the Cause of Genitourinary Symptoms in Women in a Family Practice: Comparison of Clinical Examination and Comprehensive Microbiology. JAMA. 1984;251(5):620-5.

2. Mitra SK, Sunitha A, Vijaykumar V, Pooranesan R, Satyarup S. Multicentric Trial on the Effect of V-Gel (PD-959 Gel) in Vaginitis. The Ind Pract. 1997;50:951. 
3. Wang FJ, Zhang D, Liu ZH, Wu WX, Bai HH, Dong HY. Species Distribution and In Vitro Antifungal Susceptibility of Vulvovaginal Candida Isolates in China. Chin Med J (Engl). 2016;129(10):1161-5.

4. Allison DL, Willems HM, Jayatilake JA, Bruno VM, Peters BM, Shirtliff ME. Candida-Bacteria Interactions: Their Impact on Human Disease. Microbiol Spectr. 2016 Jun;4(3).

5. Sobue S, Sekiguchi K. Difference in percutaneous absorption and intracutaneous distribution in guinea pigs among topical antifungal drugs (tioconazole solution, tioconazole cream, miconazole nitrate solution and bifonazole solution). Biol Pharm Bull. 2004;27(9):1428-32.

6. Stein GE, Gurwith D, Mummaw N, Gurwith M. Single-Dose Tioconazole Compared with 3-Day Clotrimazole Treatment in Vulvovaginal Candidiasis. Antimicrob Agents Chemother. 1986;29(6):969-71

7. Liu XP, Fan SR, Peng YT, Zhang HP. Species distribution and susceptibility of Candida isolates from patient with vulvovaginal candidiasis in Southern China from 2003 to 2012. J Mycol Med. 2014 Jun;24(2):106-11.

8. Nagashima M, Yamagishi Y, Mikamo H. Antifungal susceptibilities of Candida species isolated from the patients with vaginal candidiasis. J Infect Chemother. 2016 Feb;22(2):124-6.

9. Shi XY, Yang YP, Zhang Y, Li W, Wang JD, Huang WM, Fan YM. Molecular identification and antifungal susceptibility of 186 Candida isolates from vulvovaginal candidiasis in southern China. J Med Microbiol. 2015 Apr;64(Pt 4):390-3.

10. Palmeira-de-Oliveira R, Palmeira-de-Oliveira A, Martinez-de-Oliveira J. New strategies for local treatment of vaginal infections. Adv Drug Deliv Rev. 2015 Sep 15;92:105-22.

11. Alfouzan W, Dhar R, Ashkanani H, Gupta M, Rachel C, Khan ZU. Species spectrum and antifungal susceptibility profile of vaginal isolates of Candida in Kuwait. J Mycol Med. 2015 Mar;25(1):23-8.

12. Leusink P, Kaptheijns A, Laan E, van Boven K, Lagro-Janssen A. Comorbidities Among Women With Vulvovaginal Complaints in Family Practice. J Sex Med. 2016 Feb;13(2):220-5.

Cite this article as: Mayekar RV, Kandhari KV, Bhosale AA, Nandanwar YS, Gaikwad SM. A prospective study to compare the efficacy and safety of tioconazole and clotrimazole vaginal gel in patients suffering from vulvovaginal candidiasis. Int J Reprod Contracept Obstet Gynecol 2016;5:4184-8. 